\title{
Influence of depth on induced geo-mechanical, chemical, and thermal poromechanical effects
}

\author{
Nnamdi E. Ezendiokwere ${ }^{1} \cdot$ Victor J. Aimikhe ${ }^{2} \cdot$ Adewale Dosunmu $^{2} \cdot$ Ogbonna F. Joel $^{2}$
}

Received: 23 October 2020 / Accepted: 28 April 2021 / Published online: 14 May 2021

(c) The Author(s) 2021

\begin{abstract}
Delivering efficient and cost-effective drilled and excavated holes require effective prediction of instability along the hole profile. Most drilled and excavated hole stability analyses in the literature are performed for a given zone without considering the influence of depth. This study focused on determining the influence of depth on induced geo-mechanical, chemical, and thermal stresses and strains in drilled or excavated holes. To this end, a new porochemothermoelastic model was developed based on extended poroelastic theory, and the developed model was employed in determining induced strains and stresses for an oil and gas well case study, using data from the literature. The study delineated the different significance levels of geo-thermal-, chemical-, and thermal-induced strains and stresses as depth increased. From the results obtained, it was clear that at shallow depths, chemically induced strains and stress were the most significant formation perturbations responsible for instability of drilled and excavated holes. On the other hand, at deeper depths, geo-mechanical-induced strains and stress were the most predominant. Comparatively, thermally induced strains and stresses were found to be the least significant formation perturbations responsible for instability of drilled and excavated holes. For this case study, the results indicated that chemical strains and stresses were more prominent at depths below $170 \mathrm{~m}$, accounting for more than $50 \%$ of the total stresses and strains. At $170 \mathrm{~m}$, both chemical and geo-mechanical stress and strain had equal contributions to the overall stress and strain. However, as depth increased, the percentage contribution of the geo-mechanical component increased and accounted for about $80 \%$ of the total strains and stresses at $1000 \mathrm{~m}$, which increased to $98.48 \%$ at depths of $6000 \mathrm{~m}$ and beyond. The findings of this study will provide guide for future studies on the application of extended poroelasticity theory in solving instability problems of drilled and excavated holes.
\end{abstract}

Keywords Depth $\cdot$ Stress $\cdot$ Strain $\cdot$ Poroelasticity $\cdot$ Porochemothermoelasticity $\cdot$ Borehole stability

Nnamdi E. Ezendiokwere

nnamdi_ezendiokwere@uniport.edu.ng

Victor J. Aimikhe

victor.aimikhe@uniport.edu.ng

Adewale Dosunmu

adewale.dosunmu@uniport.edu.ng

Ogbonna F. Joel

ogbonna.joel@uinport.edu.ng

1 World Bank Africa Centre of Excellence, Centre for Oilfield Chemicals Research, The University of Port Harcourt, Port Harcourt, Nigeria

2 Department of Petroleum and Gas Engineering, The University of Port Harcourt, Port Harcourt, Nigeria

\section{Introduction}

Apart from rare surface deposits, most precious minerals and resources on earth are usually found in subsurface deposits around the world. They are normally explored using a combination of gravimetric, magnetic, and acoustic techniques. For minerals found as fluids like oil and gas, wells are usually drilled from the surface to intercept target subsurface reservoirs. However, open-pit mining was the first method of exploitation adopted for the solid minerals (Ranjith et al. 2017), as some of them were found in deposits very close to the surface. As minerals that are found relatively close to the surface were quickly depleted, exploitation has gradually become more of underground mining. Currently, there are more active underground mines of different minerals scattered around the world than open-pit mines (Ranjith et al.

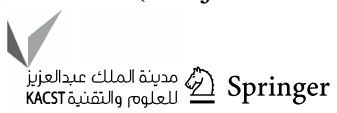


2017). Figure 1 shows current deepest depths for different subsurface resources.

Before exploitation using any method, the earth barrier obstructing easy recovery of the minerals needs to be removed. This entails reaching the target deposit or reservoir through drilled holes or excavations. This action is usually achieved either by creating boreholes in the earth or by excavating large tons of earth in open-pits or tunnels. While making boreholes using drill bits, making excavations manually or using tunneling machines, a hole of a desirable size is usually made. This involves cutting through layers of earth and rocks of varying strength and weakness. One of the commonest challenges of making drilled holes or excavations in the earth is the tendency for different sections to collapse or fail. This manifests in the form of landslides in openpit mines, collapse of underground mines (Niu et al. 2011), reduction or expansion in drilled hole sizes while drilling oil and gas wells, etc. (Weijermars et al. 2020). The failure of

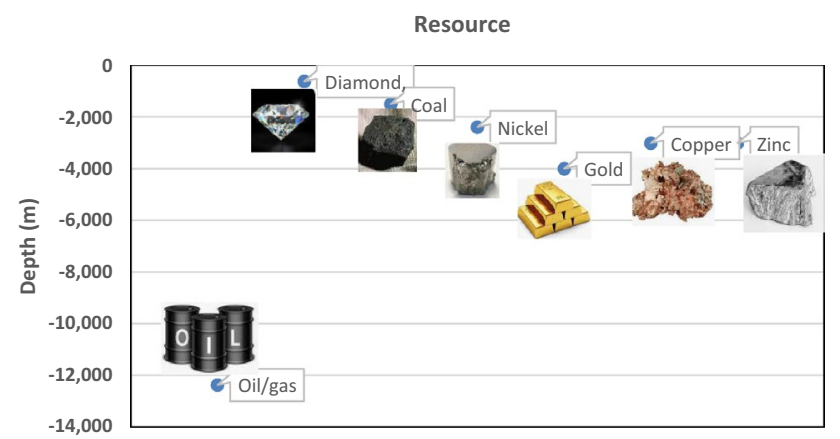

Fig. 1 Deepest depths of subsurface resources

(a) In gauge hole

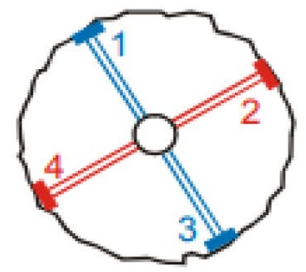

Caliper

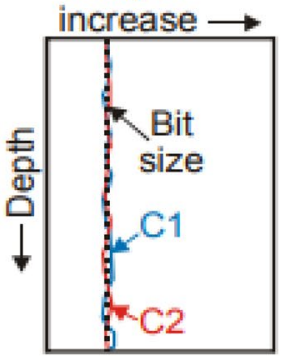

(b) Breakout

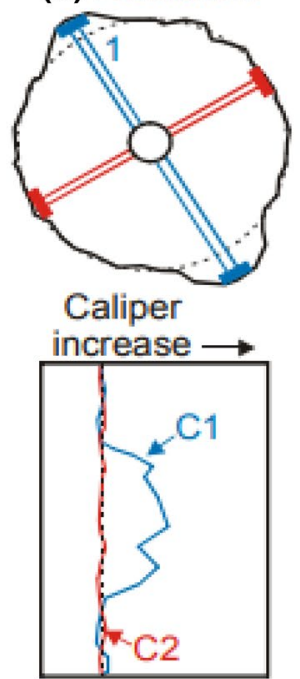

different hole sections during or after drilling or excavation is generally called drilled or excavated hole instability.

Drilled or excavated hole instability is a condition where the size of a drilled or excavated hole becomes markedly different from the intended size, thereby resulting in the hole losing its structural integrity ( $\mathrm{Li}$ and Weijermars 2019; Mehrabian et al. 2020). It is caused when the mechanical stress induced by drilling or excavation exceeds formation rock strength. The factors affecting the stability of drilled or excavated holes can be grouped into controllable and uncontrollable factors. Uncontrollable factors result from naturally induced abnormal formation in situ stress patterns like naturally fractured formations, tectonically stressed formations, etc. Controllable factors are usually the side effects of drilling or excavation operations, including bottomhole pressures (mud density), rock-fluid interactions, hole inclination and trajectory, etc. Figure 2 shows caliper log representations of different forms of borehole instability, including breakout, washout, and keyseat compared to an in-gauge hole. Interestingly, about $90 \%$ of drilled or excavated hole instability problems occur in clay or shale because this type of formation makes up about three-fourths of all drilled or excavated formations (Chen et al. 2003).

Clayey or shale formation is described as low-permeability sedimentary rocks with small pore radii characterized by medium porosity and medium to high clay content. Shale is known as a problematic rock in engineering applications with delicate and complicated behavior. Compared to other sedimentary rock types like limestone and sandstone, it is more complicated because a good knowledge of site engineering geology and the rock mechanical properties of shale specimen is not usually enough for successful engineering design (Farrokhrouz and Asef 2013). According to

(c) Washout

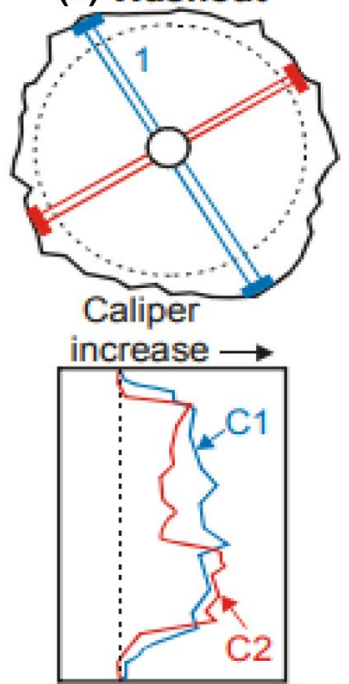

(d) Key seat

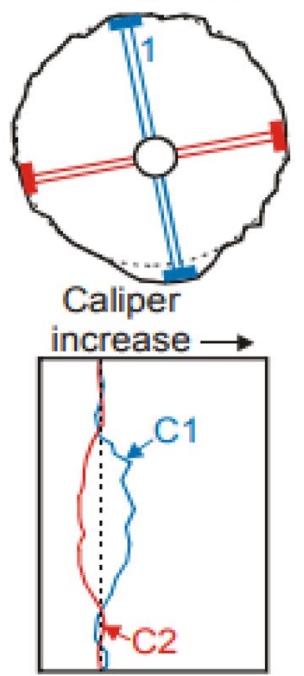

Fig. 2 Caliper log responses due to borehole enlargement (Reinecker et al. 2003) 
Farrokhrouz and Asef (2013), the different forms of drilled or excavated hole instability associated with shale or clay can be grouped into three types. The first group comprises mechanical in situ stresses and rock strength. Also, there are chemical sensitivity and swelling resulting from interaction with an invading fluid, in addition to thermal-induced stresses. Rock failure mechanisms become complicated when thermally induced stresses due to invading fluid-formation temperature differences are considered.

Carter and Booker (1982) carried out one of the earliest pore pressure and time-dependent stress analyses for excavations. They developed analytical solutions for circular tunnels in fluid-saturated media. Detournay and Cheng (1988) also developed non-hydrostatic analytical solutions for vertical wells. They showed that shear failure could also be initiated both on wellbore walls and within the formation. Cui et al. (1997) provided analytical solutions for isotropic porous media while considering wellbore inclination. The solutions were later extended to account for transitropic conditions (Abousleiman and Cui 1998) and time-dependent effects (Ekbote et al. 2004). Wilson and Aifantis (1982) developed hydrostatic dual-porosity analytical solutions for vertical wellbores in naturally fractured formations, while Li (2003) developed similar solutions but considered nonhydrostatic stress conditions.

Abousleiman and Nguyen (2005) presented threedimensional analytical solutions for inclined wells in naturally fractured formation. Dual-porosity consideration predicted narrower mud-weight windows than single-porosity (Nguyen et al. 2009; Nguyen and Abousleiman 2009). Other analytical solutions were equally developed for inclined wells while considering chemo-electrical and thermal effects (Nguyen and Abousleiman 2010; Ekbote and Abousleiman 2005, 2006).

The building block of most of these borehole instability models is Biot's poroelasticity theory of 1941. Although the theory was initially used in describing three-dimensional soil consolidation (Biot 1941), it was hugely successful that it had found widespread applications in diverse areas. These new areas of application are usually replete with porous materials having fluid-filled pores, including soil, rocks, bones, etc. (Cheng 2016). Refer to Fig. 2 description: Caliper log response due to borehole enlargement (Reinecker et al. 2003). Following the successful application of poroelasticity theory to borehole stability analysis, other extended forms of the theory quickly emerged. This was borne out of the fact that pure poroelastic analysis could not possibly explain borehole instability associated with chemically reactive formations and regions with unusually high subsurface temperatures (Cheng 2016). Numerous experimental pieces of evidence describing how chemical inhomogeneity and thermal imbalances downhole equally cause induced pore pressures have been presented (Kanfar et al. 2017). These various dimensions of addressing borehole instability led to poromechanics analyses under different names like porochemoelasticity (Ekbote and Abousleiman 2006), porothermoelasticity (Jaeger et al. 2010), porochemothermoelasticity (Ekbote and Abousleiman 2005), etc. The title of each suggesting the different types of porophysical phenomena is considered (Figs. 3, 4).

One of the commonest poromechanics phenomenon now considered in many extended forms of Biot's poromechanics theory is the chemical expansivity of argillaceous formations like shale on exposure to water. The chemical reactivity in these formations has been attributed to the presence of clay particles, which are responsible for volumetric changes that depends on water activity imbalances. When the formation water activity is higher than the water activity of invading fluid, positive volumetric changes (swelling) occur and vice versa (Luo et al. 2017). However, according to Cheng (2016), the mechanism of clay swelling can be divided into inner crystalline and osmotic swelling. Inner crystalline swelling occurs when water molecules invade the interlayer spaces between the silicate sheets of chemically sensitive formations in a process called absorption. This absorption process is known to result in swelling stresses of up to $100 \mathrm{~N} / \mathrm{mm}^{2}$. But osmotic swelling takes place when electric double layers of silicate sheets repel themselves causing swelling, while water molecules trapped in this cloud of ions is said to be adsorbed. Osmotic swelling occurs over a larger distance compared to inner crystalline swelling, but its generated swelling stress is smaller than inner crystalline swelling stress-less than $2 \mathrm{~N} / \mathrm{mm}^{2}$ (Cheng 2016).

While it is true that one porophysical phenomenon might be significant in one area and insignificant in another, the fact remains that a complete analysis should include as many phenomena as possible. More so, a tripartite analysis involving geo-mechanical, chemical, and thermal variables becomes imperative given that the effects of these phenomena change as depth increases (Han et al. 2019). For instance, geological evidence abounds on the gradual transformation of compacted shale (found at shallower depths) to cemented shale (commonly found at deeper depths) as depth increases (Farrokhrouz and Asef 2013). This is exemplified by the conversion of smectite to illite with increased temperature and pressure at greater depth. Also, considering common geological temperature gradients, the effects of drilling mud temperature in oil and gas wells become more significant as greater depths are drilled (Jaeger et al. 2010).

However, most research on the analysis of borehole instability based on poroelasticity theory or one of its extended forms like Ekbote and Abousleiman (2005), Kanfar et al. (2017) and Li and Weijermars (2019), only consider effective hoop, radial, and tangential stresses at a given zone without considering the influence of depth. In addition, other poromechanicsbased treatments of drilled or excavated hole instability in the

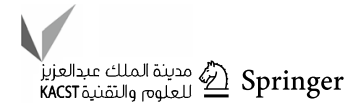


(a)

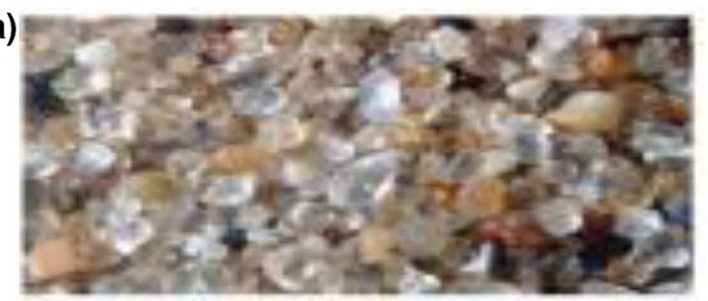

(c)

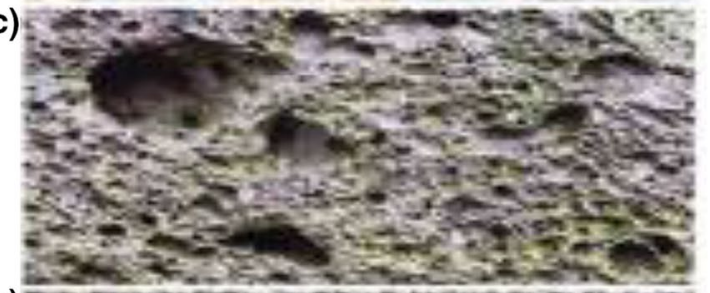

(e)

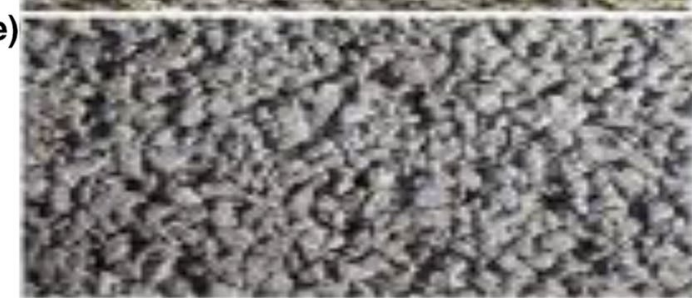

\section{(g)}

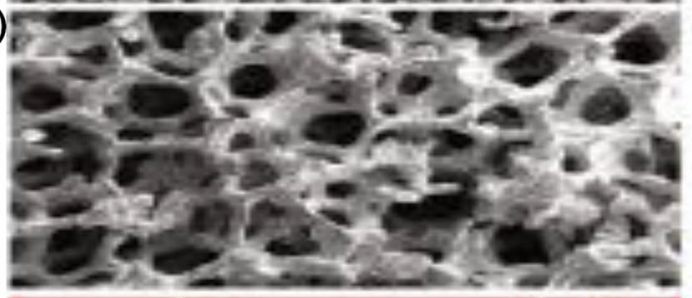

(i)

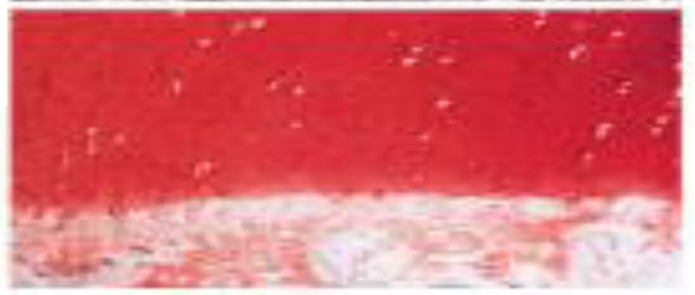

(b)

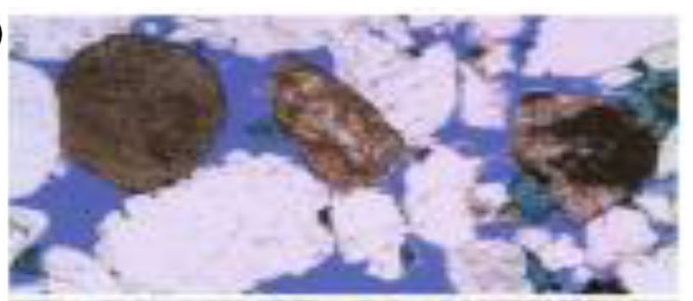

(d)

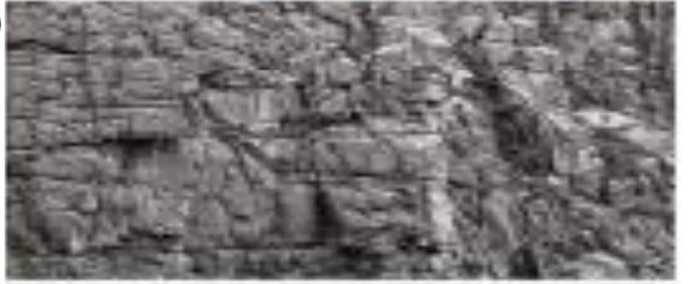

(f)

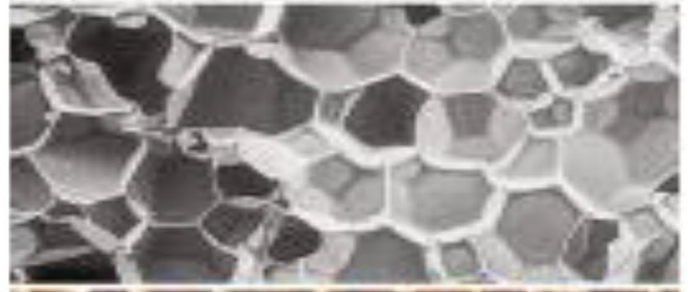

(h)

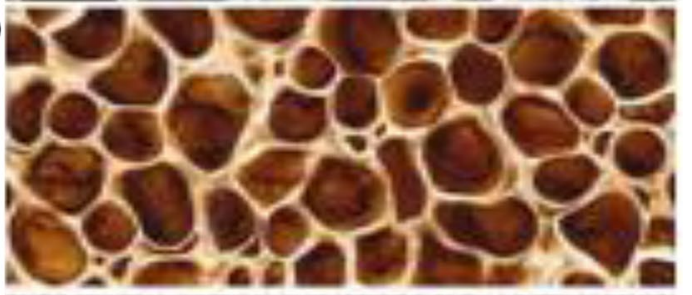

(j)

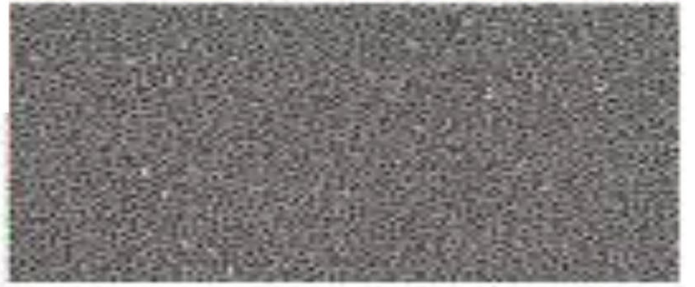

Fig. 3 Various porous materials. a Sand, $\mathbf{b}$ sandstone, $\mathbf{c}$ volcanic rock, $\mathbf{d}$ fractured rock, $\mathbf{e}$ pervious concrete, $\mathbf{f}$ polyurethane foam, $\mathbf{g}$ metal foam, $\mathbf{h}$ bone with osteoporosis, $\mathbf{i}$ articular cartilage, $\mathbf{j}$ nanoporous alumina (Cheng 2016)

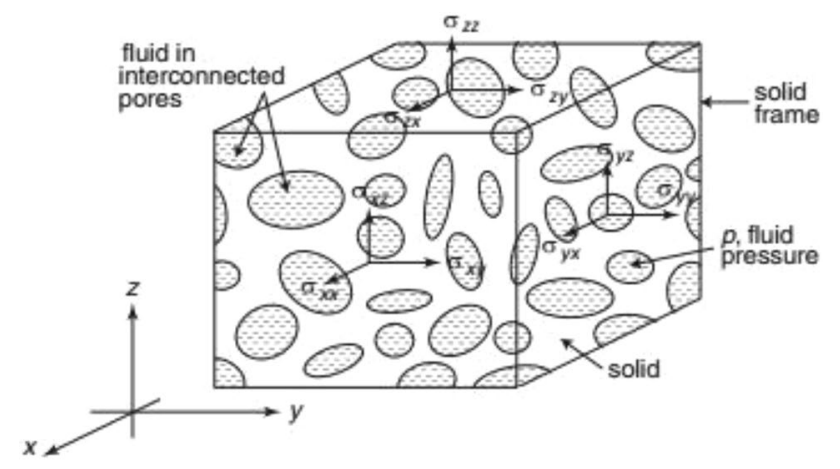

Fig. 4 Total stress tensor on a fluid-filled porous representative elemental volume (Cheng 2016)

1

SATringer industry usually do not isolate induced stresses and strains from residual stresses and strains. This seemingly overlooked void is what this study seeks to fill using isotropic conditions and a simplified procedure. By focusing on induced stresses and strains in this study, due attention is given to the part of the total stresses and strains really responsible for instability. First, a novel model for borehole stability is developed, and the effect of depth on induced stress and strain is evaluated. 


\section{Model development}

When carrying out poromechanical studies, a number of assumptions are frequently made. Following the classical Biot's poroelasticity theory, the following assumptions were made in this study:

An isotropic, porous, fluid-filled continuous solid medium is assumed with a Cauchy stress distribution. Hence, average stresses on planes within and on its surface are treated as forces per unit area.

Essentially, the stresses are also assumed to be borne by both the infiltrating fluid and the solid skeleton.

Only small strains are considered, meaning that components of strain and the projections of displacement with its first derivatives in a given direction are linear.

The solid medium follows the generalized Hooke's law and, therefore, its stress-strain relations are equally linear. Apart from mechanical homogeneity, the solid also exhibits chemical and thermal homogeneity, such that it deforms in a geometrically self-similar way.

The fluid occupying the pore spaces does not chemically react with the solid skeleton.

Upon imposition of the various porophysical stresses, only the final equilibrium states are important. As such, viscoelastic effects and time-dependency are not considered.

Assuming only small strains, the general Hooke's law for an isotropic elastic body can be written in principal coordinates as (Jaeger et al. 2010):

$\sigma_{1}=(\lambda+2 G) \varepsilon_{1}+\lambda \varepsilon_{2}+\lambda \varepsilon_{3}$

$\sigma_{2}=\lambda \varepsilon_{1}+(\lambda+2 G) \varepsilon_{2}+\lambda \varepsilon_{3}$

$\sigma_{3}=\lambda \varepsilon_{1}+\lambda \varepsilon_{2}+(\lambda+2 G) \varepsilon_{3}$

where $\sigma_{1}, \sigma_{2}, \sigma_{3}$ are three principal stresses and $\varepsilon_{1}, \varepsilon_{2}, \varepsilon_{3}$ are the principal strains. Also, $G$ is the shear modulus, and $\lambda$ is the first Lamé parameter.

Recall that volumetric strain equals the sum of three normal strains,

$\varepsilon_{v}=\varepsilon_{1}+\varepsilon_{2}+\varepsilon_{3}$

Then Eqs. (1)-(3), on substituting for $\varepsilon_{v}$, can be written as:

$\sigma_{1}=\lambda \varepsilon_{v}+2 G \varepsilon_{1}$

$\sigma_{2}=\lambda \varepsilon_{v}+2 G \varepsilon_{2}$

$\sigma_{3}=\lambda \varepsilon_{v}+2 G \varepsilon_{3}$
Consequently, after dropping $\sigma_{i}$ in favor of the more descriptive matrix terms, $\boldsymbol{\tau}_{i j}$, for stress, Eqs. (5)-(7) is written more compactly in a matrix form as:

$\tau=\lambda \operatorname{trace}(\varepsilon) \mathrm{I}+2 G \varepsilon$

When written out term by term in the general case when the coordinate system is not aligned with principal axes, Eq. (8) takes the following form:

$\tau_{x x}=(\lambda+2 G) \varepsilon_{x x}+\lambda \varepsilon_{y y}+\lambda \varepsilon_{z z}$

$\tau_{y y}=\lambda \varepsilon_{x x}+(\lambda+2 G) \varepsilon_{y y}+\lambda \varepsilon_{z z}$

$\tau_{z z}=\lambda \varepsilon_{x x}+\lambda \varepsilon_{y y}+(\lambda+2 G) \varepsilon_{z z}$

$\tau_{x y}=2 G \varepsilon_{x y} \tau_{x z}=2 G \varepsilon_{x z} \tau_{y z}=2 G \varepsilon_{y z}$

On inverting the above expressions of Hooke's law and making strains the subject, we have:

$\varepsilon_{x x}=\frac{1}{E} \tau_{x x}-\frac{v}{E} \tau_{y y}-\frac{v}{E} \tau_{z z}=\frac{1}{E}\left[\tau_{x x}-v\left(\tau_{y y}+\tau_{z z}\right)\right]$

$\varepsilon_{y y}=\frac{1}{E} \tau_{y y}-\frac{v}{E} \tau_{x x}-\frac{v}{E} \tau_{z z}=\frac{1}{E}\left[\tau_{y y}-v\left(\tau_{x x}+\tau_{z z}\right)\right]$

$\varepsilon_{z z}=\frac{1}{E} \tau_{z z}-\frac{v}{E} \tau_{x x}-\frac{v}{E} \tau_{y y}=\frac{1}{E}\left[\tau_{z z}-v\left(\tau_{x x}+\tau_{y y}\right)\right]$

$\varepsilon_{x y}=\frac{\tau_{x y}}{2 G} \varepsilon_{x z}=\frac{\tau_{x z}}{2 G} \varepsilon_{y z}=\frac{\tau_{y z}}{2 G}$

where $E=$ modulus of elasticity, $v=$ Poisson's ratio and $E=2 G(1+v)$.

\section{Constitutive equations}

To develop a linearized, non-hydrostatic theory of porochemothermoelasticity, we start by recasting Hooke's law in terms of strain using shear modulus $G$ and Poisson ratio $v$ :

$\varepsilon_{x x}=\frac{1}{2 G}\left[\tau_{x x}-\frac{v}{(1+v)}\left(\tau_{x x}+\tau_{y y}+\tau_{z z}\right)\right]$

$\varepsilon_{y y}=\frac{1}{2 G}\left[\tau_{y y}-\frac{v}{(1+v)}\left(\tau_{x x}+\tau_{y y}+\tau_{z z}\right)\right]$

$\varepsilon_{z z}=\frac{1}{2 G}\left[\tau_{z z}-\frac{v}{(1+v)}\left(\tau_{x x}+\tau_{y y}+\tau_{z z}\right)\right]$ 
$\varepsilon_{x y}=\frac{\tau_{x y}}{2 G} \varepsilon_{x z}=\frac{\tau_{x z}}{2 G} \varepsilon_{y z}=\frac{\tau_{y z}}{2 G}$

The above equations can be reduced in matrix notation:

$\varepsilon=\frac{1}{2 G} \tau-\frac{v}{2 G(1+v)} \operatorname{trace}(\tau) I$

where the identity matrix, $\boldsymbol{I}$, is given by:

$\boldsymbol{I}=\left[\begin{array}{lll}1 & 0 & 0 \\ 0 & 1 & 0 \\ 0 & 0 & 1\end{array}\right]$

\section{Components of total strain}

Stresses and strains are considered thermodynamic conjugates, such that a given strain is the result of its corresponding stress (Jaeger et al. 2010). Hence, for a tripartite treatment involving geo-mechanical, chemical, and thermal considerations with their respective stresses, there are corresponding geo-mechanical, chemical, and thermal strains. Therefore, the total strain, comprising effects of geo-mechanical, chemical, and thermal stresses, is taken as the summation of pore strain, hydration strain, and thermal strains. Pore strain refers to both positive and negative reductions in pore volume in a given direction due to positive and negative changes in the pore structure under geo-mechanical effects. The pore strain was used to represent geo-mechanical strain since for mechanically homogenous materials, pore strains are consequences of changes in geo-mechanical stresses (Jaeger et al. 2010). Also, chemical strains describe both positive and negative reductions in volume in a given direction due to invading fluid (water or drilling mud) and formation chemical interactions. Thermal strains are both positive and negative reductions in volume in a given direction as a result of the temperature difference between invading fluid and formation (Cheng 2016).

If pore strain is given as $-C_{\mathrm{bp}} P_{\mathrm{p}} / 3$ (Jaeger et al. 2010), and chemical strain as $-\varpi\left(\mu_{\mathrm{s}}-\mu_{\mathrm{d}}\right) \boldsymbol{I}$ (Luo et al. 2017), then thermal strain is given as $\beta\left(T-T_{\mathrm{o}}\right) \boldsymbol{I}$ (Farrokhrouz and Asef 2013). Here, $\varpi$ is a property of a given set of shale formation and the invading fluid. The invading fluid here could be drilling mud used in oil and gas drilling, rain water infiltrating exposed open-pit mine walls or subsurface aquifer water interacting with the walls of underground mines. The parameter $\varpi$ also incorporates the membrane efficiency $\left(I_{\mathrm{m}}\right)$, measuring the suitability of the shale or clay as a semipermeable membrane (Farrokhrouz and Asef 2013). Combining the respective strains with the expression for strain,

$$
\begin{aligned}
\boldsymbol{\varepsilon}= & \frac{1}{2 G} \boldsymbol{\tau}-\frac{v}{2 G(1+v)} \operatorname{trace}(\boldsymbol{\tau}) \boldsymbol{I} \\
& -\frac{C_{\mathrm{bp}}}{3} P_{\mathrm{p}} \boldsymbol{I}-\beta\left(T-T_{\mathrm{o}}\right) \boldsymbol{I}-\varpi\left(\mu_{\mathrm{s}}-\mu_{\mathrm{d}}\right) \boldsymbol{I}
\end{aligned}
$$

Or expressed differently in terms of effective strain,

$$
\begin{aligned}
\boldsymbol{\varepsilon} & -\frac{C_{\mathrm{bp}}}{3} P_{\mathrm{p}} \boldsymbol{I}-\beta\left(T-T_{\mathrm{o}}\right) \boldsymbol{I}-\varpi\left(\mu_{\mathrm{s}}-\mu_{\mathrm{d}}\right) \boldsymbol{I} \\
& =\frac{1}{2 G} \boldsymbol{\tau}-\frac{v}{2 G(1+v)} \operatorname{trace}(\boldsymbol{\tau}) \boldsymbol{I}
\end{aligned}
$$

On successful inversion operation to express Eq. (22) in terms of stress we have,

$$
\boldsymbol{\tau}-\alpha P_{\mathrm{p}} \boldsymbol{I}-\frac{3 K \varpi R T}{V_{\mathrm{mw}}} \ln \left(\frac{a_{\mathrm{wd}}}{a_{\mathrm{ws}}}\right) \boldsymbol{I}-3 K \beta \vartheta \boldsymbol{I}=2 G \boldsymbol{\varepsilon}+\lambda \operatorname{trace}(\boldsymbol{\varepsilon}) \boldsymbol{I}
$$

where

$\left(\mu_{\mathrm{s}}-\mu_{\mathrm{d}}\right)=I_{\mathrm{m}} \frac{R T}{V_{\mathrm{mw}}} \ln \left(\frac{a_{\mathrm{wd}}}{a_{\mathrm{ws}}}\right) \vartheta=\left(T_{\mathrm{o}}-T\right)$

Presenting the above solution in a less compact form,

$\tau_{x x}-\alpha P_{\mathrm{p}}-\frac{3 K \varpi R T}{V_{\mathrm{mw}}} \ln \left(\frac{a_{\mathrm{wd}}}{a_{\mathrm{ws}}}\right)-3 K \beta \vartheta=2 G \varepsilon_{x x}+\lambda\left(\varepsilon_{x x}+\varepsilon_{y y}+\varepsilon_{z z}\right)$

$\tau_{y y}-\alpha P_{\mathrm{p}}-\frac{3 K \varpi R T}{V_{\mathrm{mw}}} \ln \left(\frac{a_{\mathrm{wd}}}{a_{\mathrm{ws}}}\right)-3 K \beta \vartheta=2 G \varepsilon_{y y}+\lambda\left(\varepsilon_{x x}+\varepsilon_{y y}+\varepsilon_{z z}\right)$

$\tau_{z z}-\alpha P_{\mathrm{p}}-\frac{3 K \varpi R T}{V_{\mathrm{mw}}} \ln \left(\frac{a_{\mathrm{wd}}}{a_{\mathrm{ws}}}\right)-3 K \beta \vartheta=2 G \varepsilon_{z z}+\lambda\left(\varepsilon_{x x}+\varepsilon_{y y}+\varepsilon_{z z}\right)$

$\tau_{x y}=2 G \varepsilon_{x y} \tau_{x z}=2 G \varepsilon_{x z} \tau_{y z}=2 G \varepsilon_{y z}$

where $\varepsilon_{i j}=$ component of strain tensor in the $i j$ direction $(-)$; $\tau_{i j}=$ component of the total stress tensor in the $i j$ direction $(-) ; v=$ Poisson's ratio of the rock sample $(-) ; E=$ Young's elastic modulus of the rock sample (MPa); $G=$ shear modulus of the rock sample $(\mathrm{MPa}) ; \lambda=$ first Lamé constant $(\mathrm{MPa}) ; C_{\mathrm{bp}}=$ pore bulk compressibility factor $\left(\mathrm{MPa}^{-1}\right)$; $P_{\mathrm{p}}=$ pore pressure $(\mathrm{MPa}) ; \alpha=$ Biot's effective stress parameter $(-) ; K=$ bulk modulus $(\mathrm{MPa}) ; \mu_{i}=$ chemical potential of component $i(\mathrm{~J} / \mathrm{mol}) ; \varpi=$ chemical expansivity $(\mathrm{mol} / \mathrm{J})$; $\beta=$ thermal expansivity $\left(\mathrm{K}^{-1}\right) ; \vartheta=$ temperature difference between drilling fluid and formation $(\mathrm{K}) ; R=$ universal gas constant $\left(\mathrm{J} \mathrm{mol}^{-1} \mathrm{~K}^{-1}\right) ; V_{\mathrm{mw}}=$ molar volume of water $\left(\mathrm{m}^{3} /\right.$ $\mathrm{mol}) ; a_{\mathrm{wd}}, a_{\mathrm{ws}}=$ drilling mud and shale water activities (-). 


\section{Materials and methods}

From the developed model, the terms on the left-hand side of Eqs. (25)-(27) are called effective stresses (Jaeger et al. 2010). The first term on the left-hand side of the equations is the stress in a given direction, and the remaining terms are induced pore pressure, chemical, and thermal stresses, which change with depth. Hence, the effective stress can be separated into a residual stress part and an induced stress part (Ranjith et al. 2017), where the residual stress represents the virgin in situ stress in a given direction before the initial stress equilibrium was upset through drilling or excavation, with the induced stress capturing the magnitude of geo-mechanical, chemical, and thermal imbalances introduced by the drilling or excavation operation. Similarly, for the effective strain equation, the residual and induced parts can equally be identified in Eq. (23). It can also be noticed from Eqs. (23) and (25)-(27) that the induced stresses appear only in the principal stress directions. This is because induced stresses are purely volumetric, and as result do not support shear stresses (Jaeger et al. 2010). From the signs of the induced stresses and strains, the equations show they are generally tensile (extensive). Hence, the induced stresses and strains were calculated from the induced parts of the effective stress and strain equations as given in Eqs. (23) and (24), while the percentage contributions of each porophysical phenomena considered were calculated from their respective contribution to the total stress and strain.

In addition, for the stress and strain sign convention, compressive stresses and strains were treated as positive, while tensile (extensive) stresses and strains were taken as negative in agreement with geomechanics convention. Table 1 shows the parameters used for the analysis in this study. The assumed values are consistent with field experience. Given available data, the case study analyzed is that of oil and gas drilling, but the results easily extend to excavations and tunnels in mines and construction works. Also, the case study involves a vertical well, but the same treatment can be extended to inclined wellbores.

Moreover, a complete description of how the total pore pressure varies depends on another set of phenomenological equations (Demirel 2007) needed for a mathematically well-posed borehole stability problem (Jaeger et al. 2010). These phenomenological equations and the accompanying Navier-type equations are beyond this study's scope. A complete porochemothermoelastic solution to borehole instability can also be found in other studies (Ekbote and Abousleiman 2005; Kanfar et al. 2017).

\section{Results and discussion}

Figures 5, 6, 7, and 8 show the geo-mechanical-, chemical-, and thermal-induced strain and stress variations with depth. In other to fully represent the observed trends, the depths were split into two: shallow and deep depths. For this study, shallow depths were taken as depths below $1000 \mathrm{~m}$ and deep depths were taken as depths above 1000 m. Hence, Figs. 5 and 6 are used to represent variations of geo-mechanical, chemical and thermal strains and stresses with depth, respectively, for shallow depths, while Figs. 7 and 8 are used to represent variations of geo-mechanical, chemical, and thermal strains and stresses with depth, respectively, for deep depths.
Table 1 Chemothermoporoelasticity parameters used for numerical analysis and their values

\begin{tabular}{|c|c|c|c|}
\hline Parameter & Symbol & Value & Source \\
\hline Biot's effective stress parameter $(-)$ & $\alpha$ & 0.966 & Farrokhrouz and Asef (2013) \\
\hline Pore pressure (MPa) & $P_{\mathrm{p}}$ & 99.55709 & Farrokhrouz and Asef (2013) \\
\hline Fluid bulk modulus (MPa) & $K_{\mathrm{f}}$ & 1099 & Farrokhrouz and Asef (2013) \\
\hline Chemical expansivity coefficient (mol/J) & $\Pi$ & $5 \times 10^{-12}$ & Jaeger et al. 2010 \\
\hline Molar volume of water $\left(\mathrm{m}^{3} / \mathrm{mol}\right)$ & $V_{\mathrm{mw}}$ & 0.000018 & Demirel (2007) \\
\hline Universal gas constant $\left(\mathrm{J} \mathrm{mol}^{-1} \mathrm{~K}^{-1}\right)$ & $R$ & 8.314 & Svanadze (2019) \\
\hline Formation temperature (K) & $T$ & 473 & Akpabio et al. (2013) \\
\hline Shale water activity $(-)$ & $a_{\mathrm{ws}}$ & 0.35 & Zhang et al. (2008) \\
\hline Drilling fluid water activity (-) & $a_{\mathrm{wd}}$ & 0.7 & Zhang et al. (2008) \\
\hline Thermal expansivity coefficient $\left(\mathrm{K}^{-1}\right)$ & $B$ & $1.8 \times 10^{-6}$ & Farrokhrouz and Asef (2013) \\
\hline Mud/formation temp. diff. (K) & $\Theta$ & 170 & Luo et al. (2017) \\
\hline Mud temperature $\left({ }^{\circ} \mathrm{C}\right)$ & $T_{\mathrm{m}}$ & 30 & Jaeger et al. 2010 \\
\hline Matrix bulk modulus (MPa) & $K_{\mathrm{m}}$ & 32,600 & Farrokhrouz and Asef (2013) \\
\hline Bulk pore compressibility $(\mathrm{MPa})^{-1}$ & $C_{\mathrm{bp}}$ & 0.000879 & Farrokhrouz and Asef (2013) \\
\hline
\end{tabular}


Fig. 5 Variation of geo-mechanical-, chemical-, and thermalinduced strains with depth at shallow depths
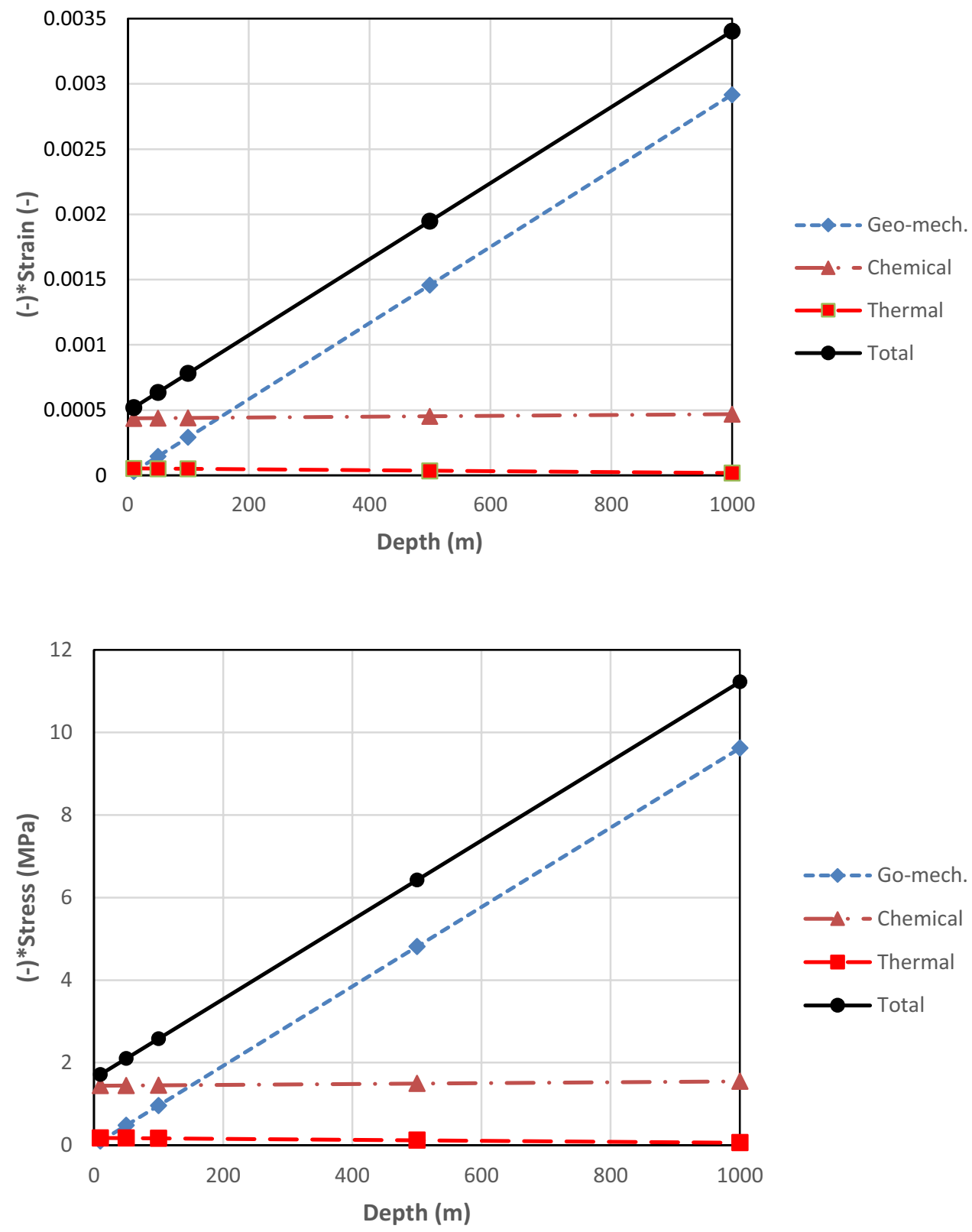

Fig. 6 Variation of geo-mechanical-, chemical-, and thermalinduced stresses with depth at shallow depths
From Figs. 5 and 6, it can be seen that total induced strains and stresses as a summation of three induced strains and stresses components vary directly with depth. This clearly shows that induced strains and stresses become significant, with increase in depth. It can equally be seen that both geo-mechanical and chemical strain and stress constituted a major part of the total induced strain and stress in drilled holes and excavations at shallow depths compared to thermal strain and stress. In fact, at depths below $170 \mathrm{~m}$, chemical strains and stresses accounted for the majority of the total strain and stress. Beyond this depth, geo-mechanical-induced strains and stresses clearly increased as depth was increasing, following the trend of the total strain and stress. The rate at which geo-mechanical strain and stress was increasing was fast enough that geo-mechanical strains and stresses quickly dwarfed the rates at which both chemical and thermal strains and stresses were changing. Making chemical and thermal strains and stresses look seeming constant over the depth range being considered.

Similar trends were also noticed for deep depths in as captured in Figs. 7 and 8. Here, geo-mechanical strain and stress followed the total strain and stress more closely compared to shallow depth, with chemical and thermal strain and stress accounting for even smaller proportions of the total strain and stress. This shows that at deeper depths, geomechanical strain and stress account for over $90 \%$ of induced stresses and strains in drilled holes and excavations. This observation agrees with typical geological gradients, which 
Fig. 7 Variation of geo-mechanical-, chemical-, and thermalinduced strains with depth at deep depths
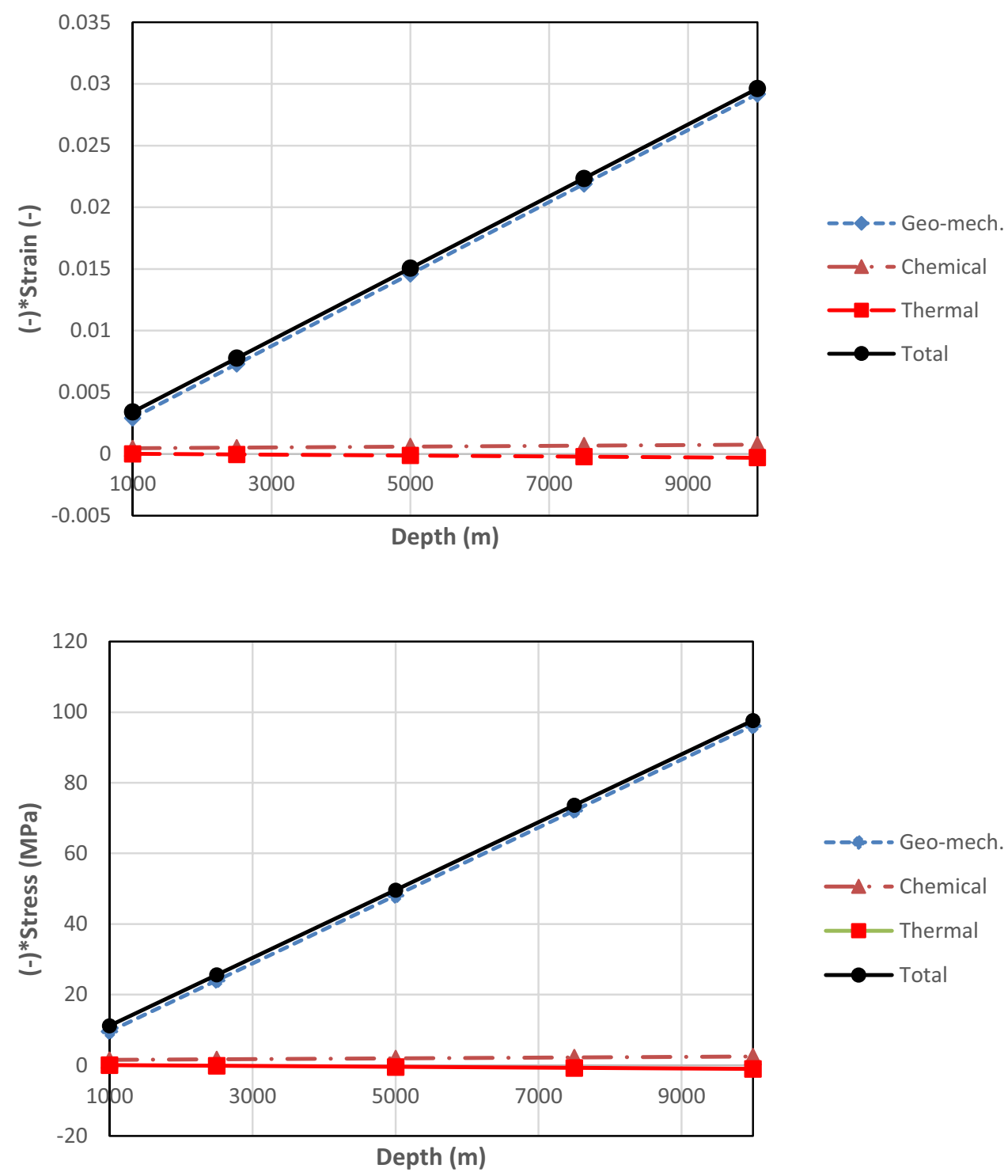

Fig. 8 Variation of geo-mechanical-, chemical-, and thermalinduced stresses with depth at deep depths indicate that geo-mechanical variables generally increase with depth (Ranjith et al. 2017). Also, the disparity between the induced strain and stress responses of the different poromechanical components at shallow and deep depths can be traced primarily to increase in overburden stress accompanying increase in depth. A careful look at depth profiles of drilled holes and excavations will reveal different layers of formation systematically placed one above the other, with the weight of overlying sections carried by lower ones. This overlying weight becomes increasing higher at increasing depth as underlying formation carries increasing overlying weight, giving rise to geo-mechanical effects as represented by in situ stresses in different directions (Dosunmu et al. 2020). Since the underlying rocks cannot undergo full strain due to adjacent rocks, this overburden stress is also translated into both maximum and minimum horizontal geomechanical stresses.
In order to get a clearer picture of the variation of chemical and thermal strain and stress with depth over the whole depth profile, Figs. 9 and 10 are plotted. Figures 9 and 10 reveal that chemical strain and stress were actually increasing with depth, but the rate of increase was below the rate of geo-mechanical strain and stress increase. On the other hand, Figs. 9 and 10 equally reveals that thermal-induced strains and stresses, however, reduced as depth increased. This reduction in thermal-induced strains and stresses does not entirely signify reduction in magnitude per se. For this case study, it was due to the changing signs of drilling mud-formation temperature difference, and not necessary a decrease in magnitude. Despite there was a decrease in magnitude of the thermal strain and stress as the tensile strain and stress reduced to zero. But as soon as the strain and stress turned negative signifying the onset of compressive strain and 
Fig. 9 Variation of chemicaland thermal-induced strains with depth at shallow and deep depths
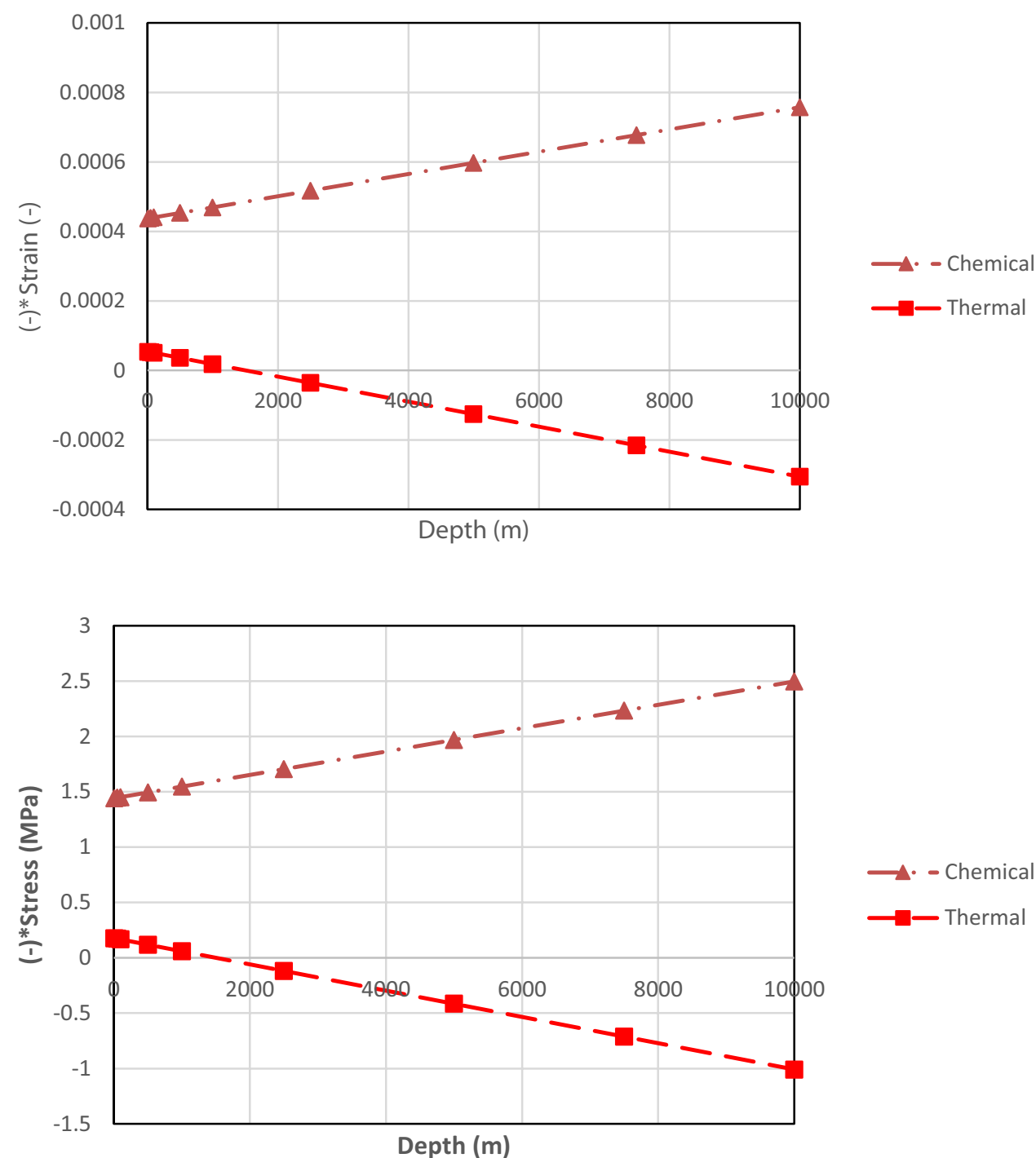

Fig. 10 Variation of chemicaland thermal-induced stresses with depth at shallow and deep depths stress, the strain and stress magnitudes then started increasing with depth.

The drilling mud-formation temperature difference gradually changed sign from positive to negative as depth increased, thereby changing thermal strain and stress from tensile or extensive at lower depths to compressive at deeper depths. The drilling mud temperature will likely be higher than formation temperature at few meters depths, especially in cold or temperate regions. Another good reason for possible higher mud temperatures at shallow depths could equally be the pumping energy delivered by the pumping system on a drilling platform. Some of which would end up being utilized to overcome frictional resistance to flow, thereby increasing the mud temperature. Since thermal strains and stresses result from thermal imbalance between drilling mud and formation, higher mud temperature will lead to tensile strains and stresses on the formation at shallow depths. At deeper depths, the thermal strain and stress become compressive (negative strains and stresses), due to likely higher temperatures.

Given that Figs. 5, 6, 7, 8, 9, and 10 also show that the rates of change in the magnitude of strain and stress for various components of induced strains and stresses were different with increase in depth, which is because each strain and stress component has a depth range for which its impact is significant (Bourgoyne et al. 1991). These varying rates of change in strain and stress informed the choice to investigate the percentage contribution of each induced strain and stress component to the total as depth increases. Figure 11 shows the relative contribution of the three induced strain and stress components.

From the statistics, it is evident that the total percentage contributions of all induced strains and stresses were equal to $100 \%$ at all depths considered. This total percentage induced strain and stress were used as checks for accuracy, as summation values different from $100 \%$ would have flagged 
Fig. 11 Variation of percentage geo-mechanical-, chemical-, and thermal-induced strains and stresses with depth

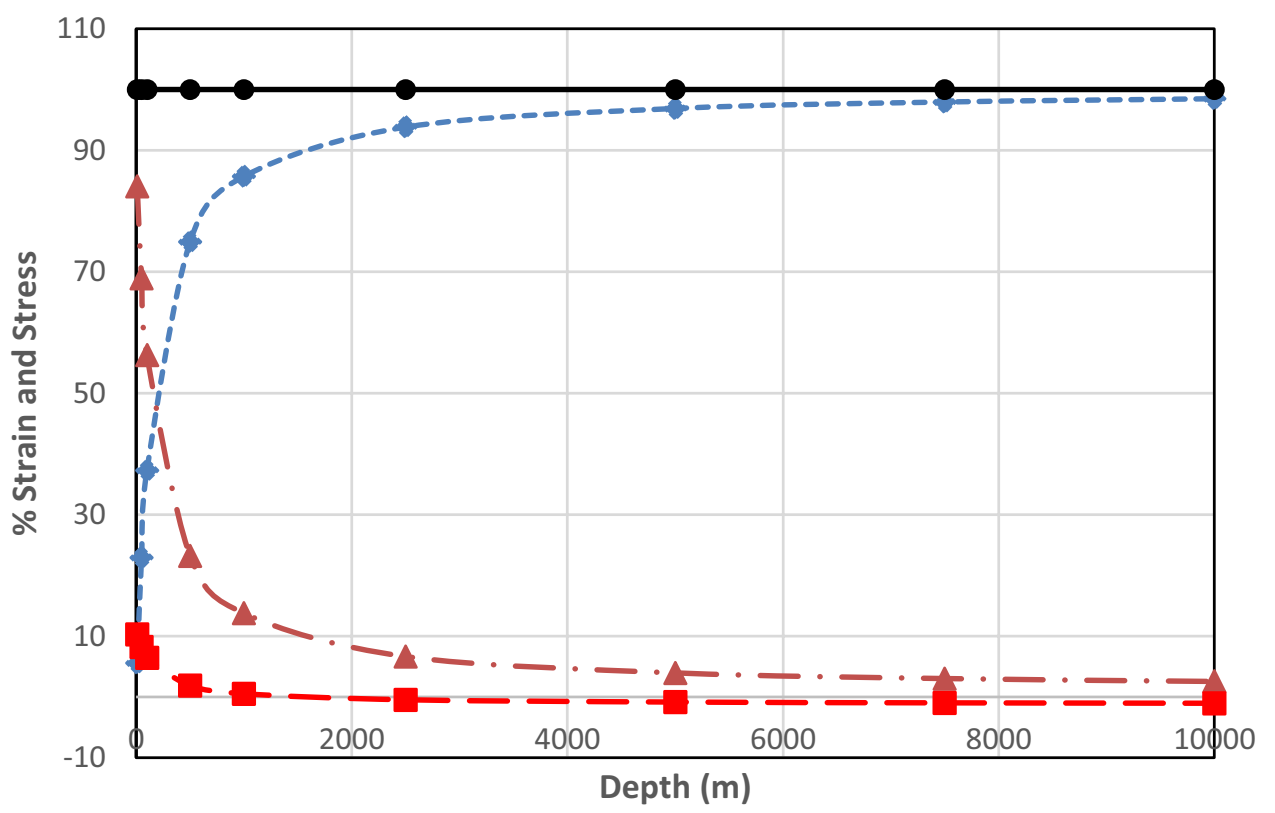

$--\rightarrow-$-Geo-mech $(\%) \longrightarrow$ - Chem $(\%) \longrightarrow$ Thermal(\%) $\longrightarrow$ Total (\%) calculation errors. However, chemical-induced strains and stresses accounted for significantly high percentage of total induced strains and stresses below $1000 \mathrm{~m}$. This was because thermally and geo-mechanically induced strain and stress percentage contributions were comparatively low below this depth. At greater depths, the percentage contributions of chemical-induced strains and stresses to total strain and stress gradually decreased, while geo-mechanical strain and stress astronomically increased with depth.

This phenomenon can be explained by the gradual transition from compacted or consolidated formation (including smectites, which are more chemically sensitive) to cemented formation (like illite, which is less chemically sensitive) as drilling depth increases. As more cemented formation is encountered at deeper depths, the percentage contributions of chemical strains and stresses to total strain and stress decrease due to a substantial reduction in porosity (Farrokhrouz and Asef 2013). This is because most wellbore stability problems are traceable to compacted chemically reactive smectite group of shales, which are usually found at shallower depths (Weijermars et al. 2020). With an increase in depth, both temperature and pressure increase, thereby increasing formation pore pressure simultaneously. Pore pressure serves as a good measure of geo-mechanical-induced strains and stresses (Jaeger et al. 2010). This increase in pore pressure due to increasing pressure and temperature following higher geo-mechanical stress at greater depths explains why the percentage contributions of geomechanical-induced strains and stresses to total induced strain and stress increased.
The percentage contributions of thermal-induced strains and stresses were the least among the three induced strain and stress components. The relatively low mud-formation temperature difference is perhaps not high enough to significantly contribute to total induced strain and stress compared to chemical and geo-mechanical components. Except where drilling mud is continuously cooled to achieve certain drilling objectives, the average mud temperature is not usually very far from average formation temperatures due to continuous conductive heat transfer along the wellbore wall. This possibly explains why thermal strains and stresses are sometimes ignored in some borehole stability analyses, especially in shallow holes and excavations. However, thermally induced strain and stress are known to be significant around radioactive waste canisters or during injection of cold water in geo-thermal wells for pressure maintenance (Jaeger et al. 2010).

For this case study, it was noticed that the chemical component of induced strain and stress accounted for more than $50 \%$ of total strains and stresses, at depths below $170 \mathrm{~m}$. Also, at $170 \mathrm{~m}$, the percentage contributions of chemicalinduced strains and stresses were the same with that of geo-mechanical strains and stresses. Particularly, the two poromechanics effects both had $46 \%$ contributions each to the total strains and stresses, with thermal-induced strains and stresses accounting for the remainder. At $1000 \mathrm{~m}$, geomechanical strain and stress component were by far the main contributors to total strains and stresses, accounting for about $70 \%$ of the total strain and stress. Chemical strains and stresses accounted for less than $30 \%$ and thermal-induced

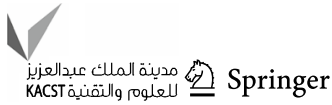


strains and stresses accounted for the balance. However, the percentage contribution of the geo-mechanical component increased to $98.48 \%$ at $6000 \mathrm{~m}$ and beyond. At this depth, the percentage contributions of the poromechanics effects of chemical and thermal strains and stresses were $2.56 \%$ and $1.03 \%$, respectively.

The results support general drilling engineering rule of thumb that most borehole stability problems encountered at mid to shallow depths are likely attributable to chemical reactivity of shale. Consequently, this study showed that at shallow depths, chemically induced strains and stresses are more likely to contribute to borehole instability, while geo-mechanically induced strains and stresses are mainly responsible for borehole instability at greater depths. Also, thermal-induced strains and stresses are less likely to result in drilled or excavated hole instability problems.

\section{Conclusion}

From the discussion above, the following conclusion can be drawn:

(a) A comprehensive drilled or excavated hole stability analysis should involve as many poromechanics phenomena as possible. Neglecting any of them in other to simplify analysis might be misleading, as even the smallest stress unaccounted for could still pose tremendous borehole stability problems.

(b) Before any given poromechanics phenomenon is declared insignificant, a stress/strain percentage contribution analysis for the intended depth profile should be done. This will reveal the significant impact of each of them on borehole stability at each depth profile zone.

(c) At shallow depths, chemically induced strains and stress are the most significant formation perturbations responsible for drilled or excavated hole instability.

(d) At deep depths, geo-mechanical-induced strains and stress are the most significant formation perturbations accounting for drilled or excavated hole instability in drilling operations or excavations.

(e) Thermally induced strains and stresses, although significant as depth increases, are the least significant formation perturbations responsible for drilled or excavated hole instability.

(f) However, the remarkably similar results of strain and stress analyses support the fact that stress and strain are exact thermodynamic conjugates.

\section{Appendix}

See Tables 2, 3, 4, and 5.
Table 2 Variation of geomechanical-, chemical-, and thermal-induced strains with depth
Table 3 Variation of geomechanical-, chemical-, and thermal-induced stresses with depth

\begin{tabular}{lllll}
\hline Depth $(\mathrm{m})$ & Geo-mech. $(-)$ & Chemical $(-)$ & Thermal $(-)$ & Total strain $(-)$ \\
\hline 10 & -0.0000291783 & -0.000437334 & -0.00005364 & -0.000520152 \\
50 & -0.0001458910 & -0.000438615 & -0.00005220 & -0.000636706 \\
100 & -0.0002917830 & -0.000440216 & -0.00005040 & -0.000782399 \\
500 & -0.0014589150 & -0.000453022 & -0.00003600 & -0.001947937 \\
1000 & -0.0029178300 & -0.000469030 & -0.00001800 & -0.003404860 \\
2500 & -0.0072945750 & -0.000517054 & +0.00003600 & -0.007775629 \\
5000 & -0.0145891500 & -0.000597093 & +0.00012600 & -0.015060243 \\
7500 & -0.0218837240 & -0.000677132 & +0.00021600 & -0.022344856 \\
10,000 & -0.0291782990 & -0.000757171 & +0.00030600 & -0.029629470 \\
\hline
\end{tabular}

\begin{tabular}{lllll}
\hline Depth $(\mathrm{m})$ & Geo-mech. $(\mathrm{MPa})$ & Chemical $(\mathrm{MPa})$ & Thermal $(\mathrm{MPa})$ & Total $(\mathrm{MPa})$ \\
\hline 10 & -0.09617 & -1.44189 & -0.176850 & -1.7149100 \\
50 & -0.48086 & -1.44611 & -0.172100 & -2.0990700 \\
100 & -0.96172 & -1.45139 & -0.166170 & -2.5792800 \\
500 & -4.80861 & -1.49361 & -0.118690 & -6.4209100 \\
1000 & -9.61721 & -1.54639 & -0.059350 & -11.222950 \\
2500 & -24.0430 & -1.70473 & +0.118692 & -25.629038 \\
5000 & -48.0861 & -1.96861 & +0.415422 & -49.639288 \\
7500 & -72.1291 & -2.23250 & +0.712152 & -73.649448 \\
10,000 & -96.1721 & -2.49639 & +1.008882 & -97.659608 \\
\hline
\end{tabular}


Table 4 Variation of percentage geo-mechanical-, chemical-, and thermal-induced strains with depth

\begin{tabular}{lllll}
\hline Depth (m) & $\begin{array}{l}\text { Geo-mech. } \\
(\%)\end{array}$ & $\begin{array}{l}\text { Chemical } \\
(\%)\end{array}$ & Thermal (\%) & Total (\%) \\
\hline 10 & 5.609568582 & 84.07806714 & 10.31236428 & 100 \\
50 & 22.91340116 & 68.88815246 & 8.198446379 & 100 \\
100 & 37.29337589 & 56.26489809 & 6.441726025 & 100 \\
500 & 74.89538933 & 23.25650162 & 1.848109051 & 100 \\
1000 & 85.69603449 & 13.77530941 & 0.528656097 & 100 \\
2500 & 93.81331079 & 6.649674258 & -0.462985052 & 100 \\
5000 & 96.87194290 & 3.964696984 & -0.836639887 & 100 \\
7500 & 97.93629460 & 3.030370838 & -0.966665437 & 100 \\
10,000 & 98.47728967 & 2.555465893 & -1.032755564 & 100 \\
\hline
\end{tabular}

Table 5 Variation of percentage geo-mechanical-, chemical-, and thermal-induced stresses with depth

\begin{tabular}{lllll}
\hline Depth $(\mathrm{m})$ & $\begin{array}{l}\text { Geo-mech. } \\
(\%)\end{array}$ & $\begin{array}{l}\text { Chemical } \\
(\%)\end{array}$ & Thermal $(\%)$ & Total $(\%)$ \\
\hline 10 & 5.607874466 & 84.07963100 & 10.31249453 & 100 \\
50 & 22.90824032 & 68.89289066 & 8.198869023 & 100 \\
100 & 37.28637449 & 56.27112993 & 6.442495580 & 100 \\
500 & 74.88985206 & 23.26165606 & 1.848491880 & 100 \\
1000 & 85.69235361 & 13.77881929 & 0.528827091 & 100 \\
2500 & 93.81155859 & 6.651556722 & -0.463115315 & 100 \\
5000 & 96.87105101 & 3.965830453 & -0.836881464 & 100 \\
7500 & 97.93569668 & 3.031251504 & -0.966948184 & 100 \\
10,000 & 98.47684418 & 2.556215462 & -1.033059645 & 100 \\
\hline
\end{tabular}

Author's contribution All the authors contributed to the final version of this manuscript. ENE did model development, formal analysis, investigation, and wrote the first draft. The first and final drafts of the article were reviewed and edited by AVJ. Research conceptualization and funding was secured by JFO. At the same time, supervision was done by AVJ, DA, and JFO.

Funding This research benefitted from sponsorship of Petroleum Technology Development Fund (PTDF), Nigeria, with Grant Number PTDF-SP\&D-AOGRG-V.III-117-011B. Grant is for experiment, data gathering, processing, and report writing.

Availability of data and materials The data associated with this manuscript was obtained from journal articles published under creative commons license. And as such, the use of data thereof still falls under the applicable approval.

\section{Declaration}

Conflict of interest The authors hereby declare no inherent conflict of interest in this study.

Open Access This article is licensed under a Creative Commons Attribution 4.0 International License, which permits use, sharing, adaptation, distribution and reproduction in any medium or format, as long as you give appropriate credit to the original author(s) and the source, provide a link to the Creative Commons licence, and indicate if changes were made. The images or other third party material in this article are included in the article's Creative Commons licence, unless indicated otherwise in a credit line to the material. If material is not included in the article's Creative Commons licence and your intended use is not permitted by statutory regulation or exceeds the permitted use, you will need to obtain permission directly from the copyright holder. To view a copy of this licence, visit http://creativecommons. org/licenses/by/4.0/.

\section{References}

Abousleiman Y, Cui L (1998) Poroelastic solutions in transversely isotropic media for wellbore and cylinder. Int J Solids Struct 35:4905-4929

Abousleiman YN, Nguyen VX (2005) Poromechanics response of inclined wellbore geometry in fractured porousmedia. J Eng Mech 131:1170-1183

Akpabio I, Ejedawe J, Ebeniro J (2013) Thermal state of the Niger Delta basin. Proceedings, Thirty-Eighth Workshop on Geothermal Reservoir Engineering, Stanford University, Stanford, California, February 11-13. SGP-TR-198

Bassey A, Dosunmu A, Buduka S (2011) Wellbore strengthening and borehole stability: a geomechanical model to increase the thin mudweight window in vertical and deviated wells. In: Nigeria annual international exhibition and conference, Abuja, July 30August 3

Biot MA (1941) General theory of three-dimensional consolidation. J Appl Phys 12:155-164

Bourgoyne AT, Millheim KK, Chenevert ME, Young FS (1991) Applied drilling engineering. Society of Petroleum Engineers, Richardson

Carter JP, Booker JR (1982) Elastic consolidation around a deep circular tunnel. Int J Solids Struct 18:1059-1074

Chen G, Chenevert ME, Sharma MM, Yu M (2003) A study of wellbore stability in shales including poroelastic, chemical, and thermal effects. J Pet Sci Eng 38:167-176

Cheng AH-D (2016) Poroelasticity. Springer International Publishing, Zurich

Cui L, Cheng AH-D, Abousleiman Y (1997) Poroelastic solutions for an inclined borehole. J Appl Mech 64:32-38

Demirel Y (2007) Non-equilibrium thermodynamics: transport and rate processes in physical, chemical and biological systems. Elsevier Publishing, London

Detournay E, Cheng AH-D (1988) Poroelastic response of a borehole in a non-hydrostatic stress field. Int J Rock Mech Min Sci Geomech Abstr 25:171-182

Dosunmu A, Nwonodi RI, Ekeinde E (2020) Analysis of the collapse gradient of deep-water horizontal wellbore and the effects of mud chemical activity and variation in water depth. Stud Geotech Mech 2020:1-10

Ekbote S, Abousleiman YN (2005) Porochemothermoelastic solution for an inclined borehole in a transversely isotropic formation. $\mathrm{J}$ Eng Mech 131:522-533

Ekbote S, Abousleiman YN (2006) Porochemoelastic solution for an inclined borehole in a transversely isotropic formation. J Eng Mech 132:754-763

Ekbote S, Abousleiman YN, Cui L, Zaman M (2004) Analyses of inclined boreholes in poroelastic media. Int J Geomech 4:178-190

Farrokhrouz M, Asef MR (2013) Shale engineering: mechanics and mechanisms. Taylor \& Francis Group, Boca Raton

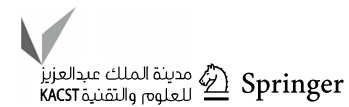


Han Y, Liu C, Phan D (2019) Advanced wellbore stability analysis for drilling naturally fractured rocks. In: SPE Middle East Oil and gas show and conference, Manama, Bahrain, March 18-21

Jaeger JC, Cook NGW, Zimmerman RW (2010) Fundamentals of rock mechanics. Blackwell, London

Kanfar MF, Chen Z, Rahman SS (2017) Analyzing wellbore stability in chemically-active anisotropic formations under thermal, hydraulic, mechanical and chemical loadings. J Nat Gas Sci Eng 41:93-111

Li X (2003) Consolidation around a borehole in a media with double porosity under release of geostatic stresses. Mech Res Commun 30:95-100

Li Y, Weijermars R (2019) Wellbore stability analysis in transverse isotropic shales withanisotropic failure criteria. J Pet Sci Eng 176:982-993

Luo X, Were P, Hou Z, Gou Y (2017) Determination of shale osmotic pressure using spontaneous potential log. Environ Earth Sci $76: 1-8$

Mehrabian A, Nguyen VX, Abousleiman YN (2020) Wellbore mechanics and stability in shale. In: Dewers T, Heath J, Sánchez M (eds) Shale: subsurface science and engineering, geophysical monograph, vol 245. Wiley, New York

Nguyen V, Abousleiman YN (2009) Poromechanics response of inclined wellbore geometry in chemically active fractured porous media. J Eng Mech 135:1281-1294

Nguyen V, Abousleiman YN (2010) Incorporating electrokinetic effects in the porochemoelastic inclined wellbore formulation and solution. An Acad Bras Ciênc 82:195-222
Nguyen V, Abousleiman YN, Hoang S (2009) Analyses of wellbore instability in drilling through chemically active fractured-rock formations. SPE J 14:283-301. https://doi.org/10.2118/105383-PA

Niu S, Jing H, Zhang Z, Yang S (2011) Study on control technology of surrounding rocksin deep soft roadway and its application. J China Coal Soc 36:914-919

Ranjith PG, Zhao J, Ju M, De Silva RVS, Rathnaweera TD, Bandara AKMS (2017) Opportunities and challenges in deep mining: a brief review. Engineering 3:546-551

Reinecker J, Tingay M, Müller B (2003) Borehole breakout analysis from four-arm caliper logs. Guidelines: four-arm caliper logs, World Stress Map Project

Svanadze M (2019) Potential method in mathematical theories of multi-porosity media. Springer, Zurich

Weijermars R, Wang J, Nelson R (2020) Stress concentrations and failure modes in horizontal wells accounting for elastic anisotropy of shale formations. Earth Sci Rev 200:102957

Wilson RK, Aifantis EC (1982) On the theory of consolidation with double porosity. Int J Eng Sci 20:1009-1035

Zhang J, Rojas JC, Clark DE (2008) Stressed shale drilling strategywater activity design improves drilling performance. SPE Drilling and Completion, pp 385-393

Publisher's Note Springer Nature remains neutral with regard to jurisdictional claims in published maps and institutional affiliations. 